\title{
Effect of glass powder and silica fume on mechanical properties and on alkali-silica reaction of recycled glass mortars
}

\author{
Zineb Douaissia ${ }^{1, *}$, Mouloud Merzoud $^{1}$, and Amar Benazzouk ${ }^{2}$ \\ ${ }^{1}$ Badji Mokhtar University, Civil Engineering Department, Pb12,Annaba 23000, Algeria. \\ ${ }^{2}$ Picardy Jules Verne University, IUT / Civil Engineering Department, Faculty street,80025, Amiens Cedex A, France
}

\begin{abstract}
In order to value glass in the production of cement and concrete. We have verified the effect of the progressive substitution of $10 \%$ to $50 \%$ of the volume of cement by glass powder and silica fume on the mechanical properties of hardened mortars, we have also verified their inhibitory effect of the Alkali Silica Reaction (ASR) by studying the variation of mass, expansion, opening and density of cracks as well as the loss of mechanical performance of mortars undergoes a test that accelerates the ASR by autoclave. We have concluded that the use of these mineral admixtures can improve the mechanical performance of mortars, and it can reduce expansions and mechanical performance losses due to ASR.
\end{abstract}

\section{Introduction}

A more pressing requirement to find an alternative to cement has been made in recent years, the focus is on the use of industrial waste such as glass. In this context, it would seem advantageous to recycle this material as a partial replacement of the cement and/or granulate. Because of its amorphous nature and containing relatively appreciable amounts of silica, glass is generally considered to be pozzolanic if it is finely ground. Thus, it could be used as a replacement for Portland cement in concrete. Several studies have been conducted on the use of glass as aggregates in concrete [1-7]. The partial replacement of the natural granulate or the cement by the glass in the concretes, improves its mechanical properties in particular the compression strengths. However, concrete has glass base are facing a problem related to their durability. The use of slightly crushed glass as sand is susceptible to the alkali-silica reaction (ASR), it is the result of the reaction of the amorphous silica of a granulate with the hydroxyl and alkaline ions present in the interstitial solution of the concrete. This reaction gives rise to a swelling gel causing the concrete to crack and in some cases its destruction [8-10].

Previous glass studies have concluded that the use of mineral admixtures such as fly ash, blast furnace slag and silica fume have a positive effect on the decrease in expansion due to ASR [11-13].

We propose in this paper to use a method based on the progressive volume substitution $(10 \%$ to $50 \%)$ of cement by glass powder and silica fume and to study their influence on the mechanical properties of hardened mortars. We also verified their inhibitory effect of ASR by studying mass variation, expansion, opening and crack density as well as the loss of mechanical performance of mortars undergoing a test that accelerates ASR by autoclave in accordance with P18594 [14].

\section{Experimental Program}

- The Portland cement used is of the CEM II / A 42.5R type manufactured at the Lafarge cement plant in Hammam Dalaâ wilaya of M'sila, Algeria.

- The granulate used is recycled sand from the glass grinding of windows, the fineness module is 2.65 .

- The glass powder (GP) is obtained by grinding glass windows until a very fine powder is obtained.

- Silica fume (SF) is a commercial product that comes from the company specialized in the manufacture of admixtures for concretes, mortars and resins "Granitex, Algeria."

Table 1. Chemical composition of materials

\begin{tabular}{lccc}
\hline & Cement & Glass & Silica fume \\
\hline $\mathrm{SiO}_{2}$ & 20.1 & 72.1 & $>95$ \\
$\mathrm{Al}_{2} \mathrm{O}_{3}$ & 5,60 & 1.00 & n.d \\
$\mathrm{Fe}_{2} \mathrm{O}_{3}$ & 2,00 & 0.10 & n.d \\
$\mathrm{CaO}$ & 62,5 & 6.30 & n.d \\
$\mathrm{MgO}$ & 3.10 & 3.70 & n.d \\
$\mathrm{K}_{2} \mathrm{O}$ & 0.90 & 0.10 & n.d \\
$\mathrm{Na}_{2} \mathrm{O}$ & 0.20 & 12.7 & n.d \\
$\mathrm{SO}_{3}$ & 3.20 & 0.10 & n.d \\
Fire loss & 1.70 & 0.40 & n.d \\
\hline
\end{tabular}

\footnotetext{
* Corresponding author: douaissiazinebgc@gmail.com
} 
The mortars were made with a replacement of $10 \%$ to $50 \%$ cement volume by one of the mineral admixtures, The composition of the mixtures is summarized in Table 2, we spoiled two mixtures, the first was without adding $\mathrm{NaOH}$, it was intended for the determination of the mechanical characteristics, the second was enriched by adding $\mathrm{NaOH}$ in the mixing water to obtain $4 \% \mathrm{Na}_{2} \mathrm{O}$ intended to verify the inhibitory effect of the alkali-silica reaction.

In aim of determine the rate of mineral admixtures required to reduce the expansion of mortar bar below the harmless threshold of $0.15 \%$ according to XP P18-594. For each mixture, three $4 \times 4 \times 16 \mathrm{~cm}$ prismatic specimens were provided for each end of the stainless steel studs for the measurement of expansions. After 24 hours of mixing, the test pieces are removed, immersed in the appropriately identified and spaced water, after 24 hours of immersion, the test pieces are removed and their initial lengths (Li) are measured. The measurement is made in the conservation room, regulated at $20{ }^{\circ} \mathrm{C}$, and this with the aid of a retractometer at $0.001 \mathrm{~mm}$ precision, a stall bar in Invar of length $\mathrm{L}=16 \mathrm{~cm}$, is used to reset the comparator of the retractometer before each measurement, whose base length L0 is $16 \mathrm{~cm}$.

Then, the test pieces are placed in the autoclave, in a vertical position. The autoclave is filled with drinking water, so that the test pieces can be covered with $3 \mathrm{~cm}$ of water. The autoclave is closed, and the heating power is adjusted so that the threshold of $0.15 \mathrm{MPa}$ of relative pressure and $127^{\circ} \mathrm{C}$ of temperature is reached one hour after switching on. After 5 hours of autoclaving maintained at the specified temperature and relative pressure, the heating is stopped and the opening of expansion valve is adjusted so as to return the atmospheric pressure in about 15 minutes. The specimens are allowed to cool in the autoclave or in a suitable container, keeping them constantly immersed in water used for autoclaving in the preservation room. The final lengths (Lf) of the test pieces are measured 18 hours after this autoclave test in the same room.

The expansion $\Delta \exp (\%)$ and the mass variation $\Delta \mathrm{m}$ (\%) are calculated by the relations (1) and (2) respectively.

$$
\begin{aligned}
& \Delta \exp =\frac{\mathrm{L}_{\mathrm{f}}-\mathrm{L}_{\mathrm{i}}}{\mathrm{L}_{0}} \times 100 \\
& \Delta m=\frac{m_{\mathrm{f}}-\mathrm{m}_{\mathrm{i}}}{m_{\mathrm{i}}} \times 100
\end{aligned}
$$

The mortar bar specimens were then subjected to bending and compression fracture tests to determine the effect of the mineral admixtures on the loss of mechanical performance of the mortars due to ASR, the losses were calculated by the difference between the affected mortars strengths and the corresponding unaffected mortars strengths.

\begin{tabular}{|c|c|c|c|c|c|c|}
\hline & \multirow[t]{2}{*}{ Mortars } & \multicolumn{3}{|c|}{ Rate $(\%)$} & \multirow[t]{2}{*}{$\mathrm{w} / \mathrm{c}$} & \multirow{2}{*}{$\begin{array}{l}\text { Density } \\
\left(\mathrm{kg} / \mathrm{m}^{3}\right)\end{array}$} \\
\hline & & CEM II & GP & SF & & \\
\hline 01 & CEM II & 100 & 0 & 0 & 0.43 & 2100 \\
\hline 02 & GP.10 & 90 & 10 & 0 & 0.53 & 2285 \\
\hline 03 & GP.20 & 80 & 20 & 0 & 0.60 & 2265 \\
\hline 04 & GP.30 & 70 & 30 & 0 & 0.69 & 2240 \\
\hline 05 & GP.40 & 60 & 40 & 0 & 0.72 & 2230 \\
\hline 06 & GP.50 & 50 & 50 & 0 & 0.78 & 2225 \\
\hline 07 & SF.10 & 90 & 0 & 10 & 0.50 & 2266 \\
\hline 08 & SF.20 & 80 & 0 & 20 & 0.58 & 2246 \\
\hline 09 & SF.30 & 70 & 0 & 30 & 0.66 & 2205 \\
\hline 10 & SF.40 & 60 & 0 & 40 & 0.73 & 2190 \\
\hline 11 & SF.50 & 50 & 0 & 50 & 0.76 & 2185 \\
\hline
\end{tabular}

Table 2. Mix proportions and density of different mortars

\section{Results And Discussions}

Influence of the mineral admixtures according to the different cement substitution rates on the expansions of the mortars due to the ASR is presented by the Fig.1. It can be noted that the mortar without mineral admixtures (V0\%) caused a significant expansion above the $0.15 \%$ limit value.

The variations of the expansions of the mortar specimens are decreasing with the volume substitution rate of cement by the mineral admixtures so the incorporation of the mineral admixtures can reduce the expansions of the mortars, and the optimal substitution rate is $30 \%$ of the glass powder and $10 \%$ of the silica fume. The inhibitory effect of ASR by mineral admixtures may explain by the fact that the incorporation of mineral admixtures leads to the formation of $\mathrm{CSH}$ by a pozzolanic reaction, these $\mathrm{CSH}$ fill the pores of the hardened cement paste, densify the structure of the paste and lead to a decrease of its porosity, thus to a decrease of the permeability, consequently, there would be a reduction of the ionic mobility hindering the migration of the alkalis towards the reactive granulates [11-13]. 


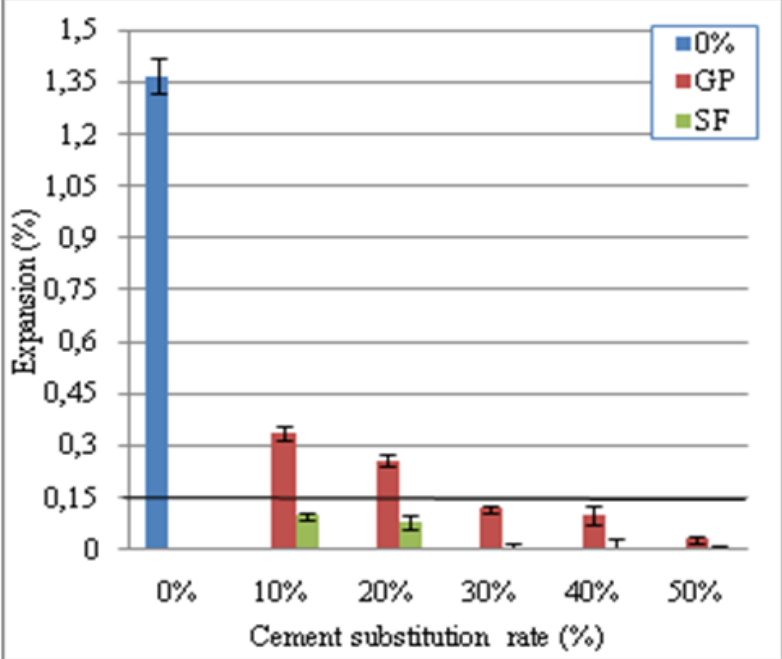

Fig 1. Effect of mineral admixtures on alkali silica reaction expansions of mortars

It can be seen in Table 3 that the major mechanical performance affected by the ASR is the flexural tensile strength, the ASR results in observed strength loss for the mortar $(0 \%)$ without mineral admixtures which are $63.6 \%$ and $18.8 \%$. bending and compression tensile respectively. This corresponds well with the results obtained by other authors [8-10], and that the incorporation of mineral admixtures has contributed to the reduction of strength loss and particularly the incorporation of silica fume.

Tensile and compressive strengths loss and modulus of elasticity loss generated by the incorporation of the glass powder, were not significant that from a $30 \%$ substitution rate of cement.

Table 3. Effect of glass powder and silica fume on the alkalisilica reaction of mortars

\begin{tabular}{|c|c|c|c|c|c|c|}
\hline \multicolumn{3}{|c|}{ Mineral admixtures } & \multicolumn{3}{|c|}{ GP } & $\mathrm{SF}$ \\
\hline \multirow{2}{*}{\multicolumn{2}{|c|}{$(\%)$}} & $0 \%$ & 10 & 20 & 30 & 10 \\
\hline & & & $\%$ & $\%$ & $\%$ & $\%$ \\
\hline \multirow{2}{*}{\multicolumn{2}{|c|}{ Mass variation (\%) }} & 4.4 & 3.4 & 1.3 & 0.9 & 0.0 \\
\hline & & 5 & 3 & 7 & 1 & 8 \\
\hline \multirow{2}{*}{\multicolumn{2}{|c|}{ Expansion (\%) }} & 1.3 & 0.3 & 0.2 & 0.1 & 0.0 \\
\hline & & 7 & 7 & 6 & 2 & 1 \\
\hline \multirow[t]{4}{*}{ Cracks } & Width (mm) & 0.9 & 0.2 & 0.1 & 0.0 & 0 \\
\hline & & 0 & 0 & 0 & 5 & \\
\hline & Density & 10. & 3.9 & 3.1 & 2.0 & 0 \\
\hline & $\left(\mathrm{mm} / \mathrm{cm}^{2}\right)$ & 9 & 4 & 2 & 0 & \\
\hline \multirow[t]{3}{*}{ Loss } & $\begin{array}{l}\text { tensile strength } \\
(\%)\end{array}$ & $\begin{array}{c}63 . \\
6\end{array}$ & 50 & 40 & 30 & - \\
\hline & $\begin{array}{l}\text { Compressive } \\
\text { strength }(\%)\end{array}$ & $\begin{array}{c}18 . \\
8\end{array}$ & 15 & 9 & 6.8 & - \\
\hline & $\begin{array}{l}\text { Elasticity } \\
\text { module (\%) }\end{array}$ & $\begin{array}{c}18 . \\
5\end{array}$ & $\begin{array}{c}13 . \\
5\end{array}$ & 9.5 & 7.8 & - \\
\hline
\end{tabular}

\section{References}

1. Y. Shao, T. Lefort, and S. Rodriguez, Cem and Conc Res, 30(1), 91 (2000).

2. Z. Bazant, and C. Meyer, J. Eng Mech, 17, 226 (2000)

3. T. D. Dyer and R. K. Dhir, J. Materials Civil Eng., 25, 412 (2001).

4. C. Meyer, and Y.P. Xi, J. Materials Civil Eng., 11-2, 89 (1999).

5. S.B. Park, B.C. Lee and J H. Kim, Cem. Conc. Res., 34-12, 2181-2189 (2004).

6. C., Shi, Y. Wu, and C. Rieflerb and H. Wang, Cem. Conc. Res, 35-5, 987 (2005).

7. A. Shayan and A. Xu, Cem. Conc. Res., 34-1, 81 (2004).

8. G. Giaccio, R. Zerbino, J.M. Ponce, O. R. Batic, Cem and Conc Rese, 38, 993-1004 (2008).

9. A.E.K. Jones, L.A. Clark, Eng. Struct., 20-9, 785 (1998).

10. R.N. Swamy, M.M. Al-Asali, American Conc. Inst. Materials J., 85-41, 367 (1989).

11. G.J.Z. Xu, D.F. Watt, P.P. Hudec, Cem and Conc Rese, 25-6, 1225-1236 (1995).

12. P.J.M. Monteiro, K. Wang, G. Sposito, M.C. Santos, W.P. Andrade, Cem. Conc. Res., 27-12, 1899 (1997)

13. R.N. Swamy and M.M. Al-Asali, $8^{\text {th }}$ ICAAR, Kyoto, Jap., 205 (1989).

14. NF P18-594 - Aggregates - Test methods on reactivity to alkalies - July, 2015. 